ARTICLE

\title{
Drugs and the kidney
}

\author{
S Naidoo, ${ }^{1}$ MB BCh, FCP (SA), Cert Nephrology (SA), MMed; A M Meyers, ${ }^{2}$ MB BCh, FCP (SA), Cert Nephrology (SA), FRCP (Lond) \\ ${ }^{1}$ School of Clinical Medicine, Faculty of Health Sciences, University of the Witwatersrand; Charlotte Maxeke Johannesburg Academic Hospital; and Wits \\ Donald Gordon Medical Centre, Johannesburg, South Africa \\ ${ }^{2}$ Donald Gordon Medical Centre, Klerksdorp Hospital, and National Kidney Foundation of South Africa, Johannesburg, South Africa
}

Corresponding author: A M Meyers (nkfsa@mweb.co.za)

This article on drug nephrotoxicity is detailed, as it is important to be fully aware of renal side-effects of drugs with regard to prevention and early diagnosis in order to manage the condition correctly. Many therapeutic agents are nephrotoxic, particularly when the serum half-life is prolonged and blood levels are raised because of decreased renal excretion. Distal nephrotoxicity is markedly enhanced when the glomerular filtration rate (GFR) is reduced and is a particular threat in elderly patients with so-called 'normal' creatinine levels. In patients of 45 - 55 years of age the GFR is reduced by about $1 \mathrm{~mL} / \mathrm{min} /$ year, so that an otherwise healthy person of 80 may have an estimated GFR (eGFR) of $<60 \mathrm{~mL} / \mathrm{min}$ or $<50 \mathrm{~mL} / \mathrm{min}$, i.e. stage 2, 3 or $3 \mathrm{~b}$ chronic kidney disease (CKD). Furthermore, other effects related to kidney dysfunction may be seen, e.g. worsening of hypertension with the use of non-steroidal anti-inflammatory drugs, increased bruising or bleeding tendency with aspirin, and hyponatraemia hypertension acidosis with angiotensin-converting enzyme inhibitors or angiotensin II receptor blockers. Digoxin is contraindicated in stage 3 CKD, even in a reduced dosage. Other drugs can cause the direct formation of kidney stones, e.g. topiramate (used in the prophylaxis of resistant migraine). Levofloxacin (Tavanic) can cause rupture of the Achilles tendon and other tendons.

Radiocontrast media must be used with care. Occasionally, strategies to prevent acute kidney insufficiency cause irreversible CKD, especially in patients with diabetes and those with myeloma who have stage $4-5 \mathrm{CKD}$. Gadolinium in its many forms (even the newer products) used as contrast medium for magnetic resonance imaging is best avoided in patients with stages 4 and 5 CKD.

S Afr Med J 2015;105(4):322. DOI:10.7196/SAMJ.9537

口串回

The kidneys are the primary organs for maintaining homoeostasis of extracellular 口. $\begin{aligned} & \text { fluid volumes. They receive } \\ & 20 \text { - } 25 \% \text { of the cardiac out- }\end{aligned}$ 口fluid volumes. They receive
$20-25 \%$ of the cardiac output. The nephron (Fig. 1), which is the functional unit of the kidney, determines the pharmacokinetics of various drugs. Each nephron is capable of producing urine and is composed of a glomerulus through which fluid is filtered from the blood and a long tubular system in which the filtered fluid is converted to urine. Surrounding the tubular system is an extensive network of capillaries - the peritubular capillary network - which is supplied with blood from the efferent arteriole,

Table 1. Pathophysiology of drug-induced nephropathy

\begin{tabular}{lll}
\hline Level of the nephron & Action & Drugs \\
\hline $\begin{array}{l}\text { Preglomerular } \\
\text { (afferent arteriole) }\end{array}$ & Afferent arteriolar constriction & Cyclosporine \\
Glomerulus & $\begin{array}{l}\text { Decreased GFR } \\
\text { (prostaglandins) } \\
\text { Glomerulonephritis }\end{array}$ & $\begin{array}{l}\text { NSAIDs } \\
\text { Gold, NSAIDs } \\
\text { Penicillamine, cisplatin }\end{array}$ \\
$\begin{array}{l}\text { Proximal tubules } \\
\text { Distal tubules }\end{array}$ & Acute tubular necrosis & Aminoglycosides, radiocontrast dyes \\
Tubules and ducts & Crystalluria & ACE inhibitors, cyclosporine \\
Interstitium & Interstitial nephritis & Acyclovir, sulphonamide \\
Renal papilla & Papillary necrosis & Penicillin, allopurinol \\
\end{tabular}

Table 2. Diuretics: Mechanism of action and indications

\begin{tabular}{lll}
\hline Diuretic & Mechanism of action & Indication \\
\hline Loop & Blocks NaK2Cl (NKCC2) transporter in the thick ascending & Fluid overload \\
& loop of Henle & Hypertension \\
& Blocks NaKCl & Hypercalcaemia \\
Thiazide & Distal convoluted tubule & Antihypertension, especially in combination with \\
& Blocks electroneutral Na/Cl exchanger $(\mathrm{NCCT})$ & ACE inhibitors/ARBs \\
& Reaches site of action in glomerular filtrate - higher doses required in & In combination with loop diuretics for profound \\
& low GFR (ineffective when serum creatinine $>200 \mu$ mol/L) & oedema \\
Amiloride & Blocks ENaC (channel for sodium secretion in collecting ducts under the & Often combined with loop diuretics or thiazide to \\
& control of aldosterone) & capitalise on potassium-sparing action
\end{tabular}


blood that has already passed through the glomerulus.

The kidneys perform two major functions. Firstly, they excrete most of the end-products of the bodily metabolism, and, secondly, they control the concentration of most of the constituents of the body fluids. In normal kidney function the counter current multiplier system, together with the reninangiotensin-aldosterone system (RAAS), involves extracellular fluid volume control, electrolyte balance, waste product excretion, drug and hormone elimination/metabolism, blood pressure (BP) and haematocrit regulation, and calcium/phosphate balance (vitamin $\mathrm{D}_{3}$ metabolism).

Therefore, the kidney is involved in absorption, distribution, metabolism, elimination, secretion and filtration, and the effects of drugs can be idiosyncratic or accumulative (Table 1).

Many drugs and their metabolites are excreted by the kidney by glomerular filtration, by tubular secretion, or in some cases by both. Renal impairment has a significant effect on clearance of these drugs, with important clinical consequences.

The glomerular filtration rate (GFR)/ estimated GFR (eGFR) is an important tool in staging chronic kidney disease (CKD).

\section{Pathophysiology of drug-induced nephropathy}

Multiple drugs can affect the same site, e.g. acute tubular necrosis, which is the commonest cause of renal failure in adults, can be caused by aminoglycosides, radiocontrast dyes and many other drugs.

A single drug can affect different sites in the kidney, e.g. non-steroidal antiinflammatory drugs (NSAIDs) can cause acute renal failure, interstitial nephritis and glomerulonephritis (Table 1).

\section{The nephron and electrolyte balance}

The different diuretics include the loop diuretics, thiazide diuretics, aldactone and osmotic agents. They can by their effect on the nephron significantly alter electrolyte balance.

The indications for diuretic use include heart failure (acute or chronic), pulmonary oedema, hypertension, nephritic syndrome, hypercalcaemia and hypercalciuria. Diuretic drugs increase urine output by the kidney, i.e. they promote diuresis. This is accomplished by altering the manner in which the kidney handles sodium. If the kidney excretes more sodium, the water excretion will also increase. Most diuretics produce diuresis by inhibiting the reabsorption of sodium at different segments of the renal tubular system. Sometimes a combination of two diuretics is given as it can be significantly more effective than either compound alone, the reason being that one nephron segment can compensate for altered sodium reabsorption at another nephron segment; therefore, blocking multiple nephron sites significantly enhances efficacy.

\section{Overall conclusions}

Cumulative event rates from the primary outcome (fatal chronic heart disease (CHD) or non-fatal myocardial infarction (MI)) of the Antihypertensive and Lipid Lowering Treatment to Prevent Heart Attack Trial (ALLHAT) treatment group, have demonstrated that because of the superiority of thiazide-type diuretics in preventing one or more major forms of cardiovascular disease (CVD) and their lower cost, they should be the drugs of choice for first-step antihypertensive drug therapy.

In Table 2 the mechanism of action and indications of diuretics are shown.

Table 3 lists the side-effects and half-life of diuretics.

Specific diuretics are listed in Table 4.

\section{Spironolactone}

Spironolactone as a class is a potassiumsparing diuretic. Its mode of action is antagonising the effect of aldosterone at levels of the mineralocorticoid receptor. The aldosterone complex translocates to the nucleus to effect gene transcription. Indications include the prevention of hypokalaemia in patients on diuretics or digoxin. It improves survival in advanced heart failure (Randomised Aldactone Evaluation Study). ${ }^{[1]}$

Spironolactone can be used as an antihypertensive (adjunctive third-line therapy for hypertension) or as a first-line drug (patients with Conn's syndrome). Another indication is for the treatment of ascites in patients with cirrhosis.

The side-effects of aldactone include antiandrogenic effects through the antagonism of dihydrotestosterone at its binding site.

Drug interactions occur with other potassium-sparing drugs, e.g. angiotensinconverting enzyme (ACE) inhibitors/angiotensin II receptor blockers (ARBs) and potassium supplements.

(LoSalt may be used as an $\mathrm{NaCl}$ substitute in cooking.)

Table 5 lists diuretic adverse effects and drug interactions.

Table 3. Side-effects and half-life of diuretics

\begin{tabular}{lll}
\hline Diuretic & Side-effect & Half-life \\
\hline Loop & - Electrolyte imbalance & Oral bioavailability between \\
& - Hypokalaemia & $10 \%$ and $90 \%$ \\
& - Volume depletion (prerenal uraemia) & Acts at luminal side of the \\
& - Tinnitus (acts within the cochlea - can synergise & thick ascending limb (NaK2Cl \\
& with aminoglycoside antibiotics & transporter) \\
& & Highly protein bound \\
& & Rebound after single dose \\
Thiazide & $\begin{array}{l}\text { Metabolic } \\
\text { - Hyperuricaemia, impaired glucose tolerance }\end{array}$ & \\
& and electrolyte disturbances (hypokalaemia and & \\
& hyponatraemia) & \\
& - Volume depletion &
\end{tabular}

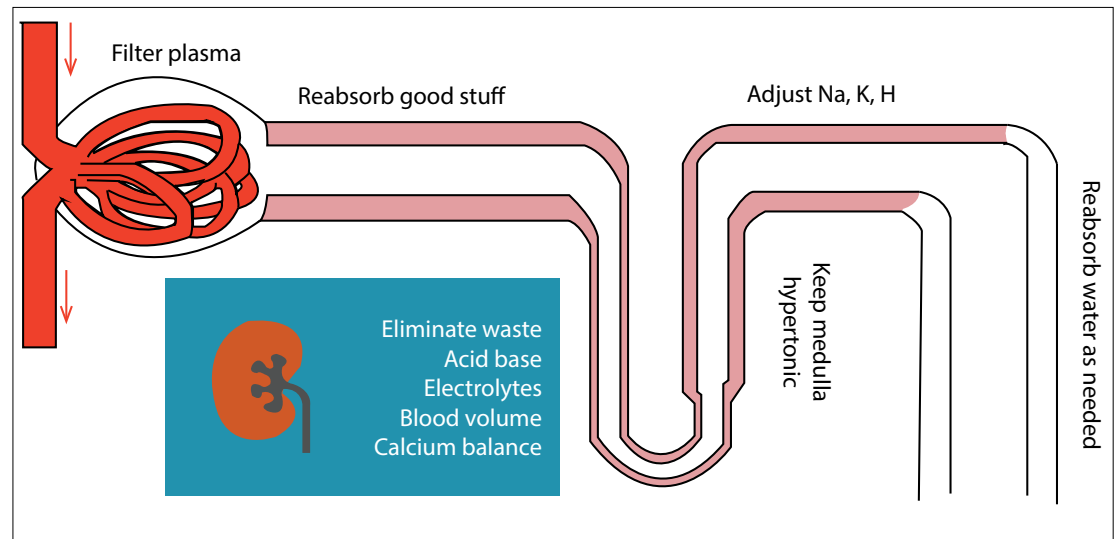

Fig. 1. The nephron. 
Table 4. Specific diuretics

\begin{tabular}{|c|c|c|}
\hline Class & Drug & Comments \\
\hline \multirow[t]{8}{*}{ Thiazide } & Chlorothiazide & \\
\hline & Chlorthalidone & Thiazide-like in action, not in structure \\
\hline & Hydrochlorothiazide & Prototypical drug \\
\hline & Hydroflumethiazide & \\
\hline & Indapamide & Thiazide-like in action, not in structure \\
\hline & Methyclothiazide & \\
\hline & Metolazone & Thiazide-like in action, not in structure \\
\hline & Polythiazide & \\
\hline \multirow[t]{4}{*}{ Loop } & Bumetanide & \\
\hline & Ethacrynic acid & \\
\hline & Furosemide & \\
\hline & Torsemide & \\
\hline \multirow[t]{4}{*}{$\mathrm{K}^{+}$-sparing } & Amioloride & Distal tubule $\mathrm{Na}^{+}$-channel inhibitor \\
\hline & Eplerenone & $\begin{array}{l}\text { Aldosterone receptor antagonist; fewer side-effects than } \\
\text { spironolactone }\end{array}$ \\
\hline & Spironolactone & $\begin{array}{l}\text { Aldosterone receptor antagonist; side-effect: } \\
\text { gynaecomastia }\end{array}$ \\
\hline & Triamterene & Distal tubule $\mathrm{Na}^{+}$-channel inhibitor \\
\hline \multirow{3}{*}{$\begin{array}{l}\text { Carbonic } \\
\text { anhydrase } \\
\text { inhibitors }\end{array}$} & Acetazolamide & $\begin{array}{l}\text { Prototypical drug; not used for treating hypertension or } \\
\text { heart failure }\end{array}$ \\
\hline & Dichlorphenamide & Not used for treating hypertension or heart failure \\
\hline & Methazolamide & Not used for treating hypertension or heart failure \\
\hline
\end{tabular}

Table 5. Adverse effects and drug interactions of diuretics

\begin{tabular}{|c|c|c|}
\hline Class & Adverse side-effects & Drug interactions \\
\hline Thiazide & $\begin{array}{l}\text { Hypokalaemia } \\
\text { Metabolic alkalosis } \\
\text { Dehydration (hypovolaemia), leading to hypotension } \\
\text { Hyponatraemia } \\
\text { Hyperglycaemia in diabetics } \\
\text { Hypercholesterolaemia, hypertriglyceridaemia } \\
\text { Increased low-density lipoproteins } \\
\text { Hyperuricaemia (at low doses) } \\
\text { Azotaemia (in renal disease) }\end{array}$ & $\begin{array}{l}\text { Hypokalaemia potentiates } \\
\text { digitalis toxicity } \\
\text { NSAIDs: reduce diuretic } \\
\text { efficacy } \\
\text { Beta-blockers: potentiate } \\
\text { hyperglycaemia, } \\
\text { hyperlipidaemias } \\
\text { Corticosteroids: enhance } \\
\text { hypokalaemia }\end{array}$ \\
\hline Loop & $\begin{array}{l}\text { Hypokalaemia } \\
\text { Metabolic alkalosis } \\
\text { Hypomagnesaemia } \\
\text { Hyperuricaemia } \\
\text { Dehydration (hypovolaemia), leading to } \\
\text { hypotension } \\
\text { Dose-related hearing loss (ototoxicity) }\end{array}$ & $\begin{array}{l}\text { Hypokalaemia potentiates } \\
\text { digitalis toxicity } \\
\text { NSAIDs: reduce diuretic } \\
\text { efficacy } \\
\text { Corticosteroids: enhance } \\
\text { hypokalaemia } \\
\text { Aminoglycosides: enhance } \\
\text { ototoxicity, nephrotoxicity }\end{array}$ \\
\hline $\mathrm{K}^{+}$-sparing & $\begin{array}{l}\text { Hyperkalaemia } \\
\text { Metabolic acidosis } \\
\text { Gynaecomastia (aldosterone antagonists) } \\
\text { Gastric problems, including peptic ulcer }\end{array}$ & $\begin{array}{l}\text { ACE inhibitors: potentiate } \\
\text { hyperkalaemia } \\
\text { NSAIDs: reduce diuretic } \\
\text { efficacy }\end{array}$ \\
\hline $\begin{array}{l}\text { Carbonic } \\
\text { anhydrase } \\
\text { inhibitors }\end{array}$ & $\begin{array}{l}\text { Hypokalaemia } \\
\text { Metabolic acidosis }\end{array}$ & \\
\hline
\end{tabular}

\section{Nephrotoxic drugs}

Nephrotoxic drugs may have a dose-dependent effect and/or cause idiosyncratic renal damage. Dose-dependent nephrotoxic drugs include NSAIDs, such as cyclo-oxygenase-2 (COX-2) inhibitors, aminoglycosides and radio-opaque contrast materials. Idiosyncratic renal damage may be secondary to NSAIDs, penicillins, gold and penicillamine.

\section{NSAIDs}

The NSAIDs are commonly used and have a wide range of pathological and physiological effects. They interfere with prostaglandin production, disrupt regulation of renal medullary blood flow and salt water balance. With habitual use they can cause chronic renal impairment. Their effect can be exacerbated by other drugs (antihypertensives, ACE inhibitors). They have typical radiological features with advanced renal dysfunction.

The pharmacology of the NSAIDs includes good absorption and hepatic metabolism, they are highly protein bound and are excreted by both enterohepatic and renal routes. Their half-lives vary. They have common therapeutic indications and adverse effects. Even though their pharmacokinetics and potencies differ and they are from different chemical families, their mechanism of action is similar. NSAIDs are cyclooxygenase inhibitors with different levels of selectivity for COX-1 and COX-2 enzymes. Their similarities are more striking than their differences.

The role of prostaglandins is described in Table 6.

Table 7 lists the functions of COX-1 and COX-2 enzymes.

NSAIDs such as ibuprofen, diclofenac and indomethacin have short half-lives, with a more rapid effect and clearance. The following NSAIDs have a longer halflife and slower onset and clearance: e.g. naprosyn, celecoxib, rofecoxib, nabumetone and piroxicam.

NSAID toxicity is wide and variable on the gastrointestinal, renal, haematological, central nervous and hepatic systems, as well as on the skin, and causes allergies.

\section{Table 6. Role of prostaglandins}

\begin{tabular}{ll}
\hline Pathological & Physiological \\
\hline - Asthma & - Temperature control \\
- Ulcers & - Bronchial tone \\
- Diarrhoea & - Cytoprotection \\
- Dysmenorrhoea & - Intestinal mobility \\
- Inflammation & - Myometrial tone \\
- Bone erosion & - Semen viability \\
- Pain & \\
- Fever &
\end{tabular}


Table 7. Functions and location of COX-1 and COX-2 enzymes

\begin{tabular}{ll}
\hline COX-1 & COX-2 \\
\hline - Constitutively expressed & - Inducible \\
- Housekeeping function & - Inflammatory \\
- Present in every organ & - Necrotic sites \\
- Stomach, kidney, intestine, platelets & - Present in the kidney \\
- Vascular endothelium & -Uterus, ovary, brain, small intestine
\end{tabular}

Table 8. NSAID classification

\section{Non-selective inhibition}

Acetic acid derivatives Proprionic acid derivatives Fenamate derivatives

- Etodolar

- Fenoprofen

- Flurbiprofen

- Ibuprofen

- Ketoprofen

- Sulindac

- Naproxen

- Oxaprozin

Naphthyl alkanone

- Nabumetone

Salicylates

- Aspirin

- Diflunisal

- Choline magnesium trisalicylate

- Salicylate

Enolic acid derivatives

- Piroxicam

- Meloxicam

Selective COX-2 inhibition

- Celecoxib

- Rofecoxib

The renal effects are secondary to lowered renal blood flow, with decreased renal prostaglandins. The risk factors are volume depletion, and renal, liver and vascular disease.

The patient with NSAID toxicity typically presents with oedema, high BP and increased creatinine levels. The following may also be present: nephrotic syndrome: interstitial nephritis; electrolyte imbalance: $\mathrm{K}^{+}$; attenuation of BP medication; papillary necrosis; and kidney stones.

The prostaglandin pathway can be seen in Fig. 2.

The classification of NSAIDs is given in Table 8.

These drugs have common drug interactions with antihypertensive treatment, phenytoin, anticoagulants and methotrexate.

NSAID-induced deterioration of renal function depends on the specific drug, the dose, the duration of the pharmacological effect, and particularly the state of health of the recipient.

Renal syndromes associated with the use of NSAIDs are:

- vasomotor acute renal failure

- nephrotic syndrome associated with interstitial nephritis

- CKD

- sodium retention

- hyponatraemia

- hyperkalaemia.

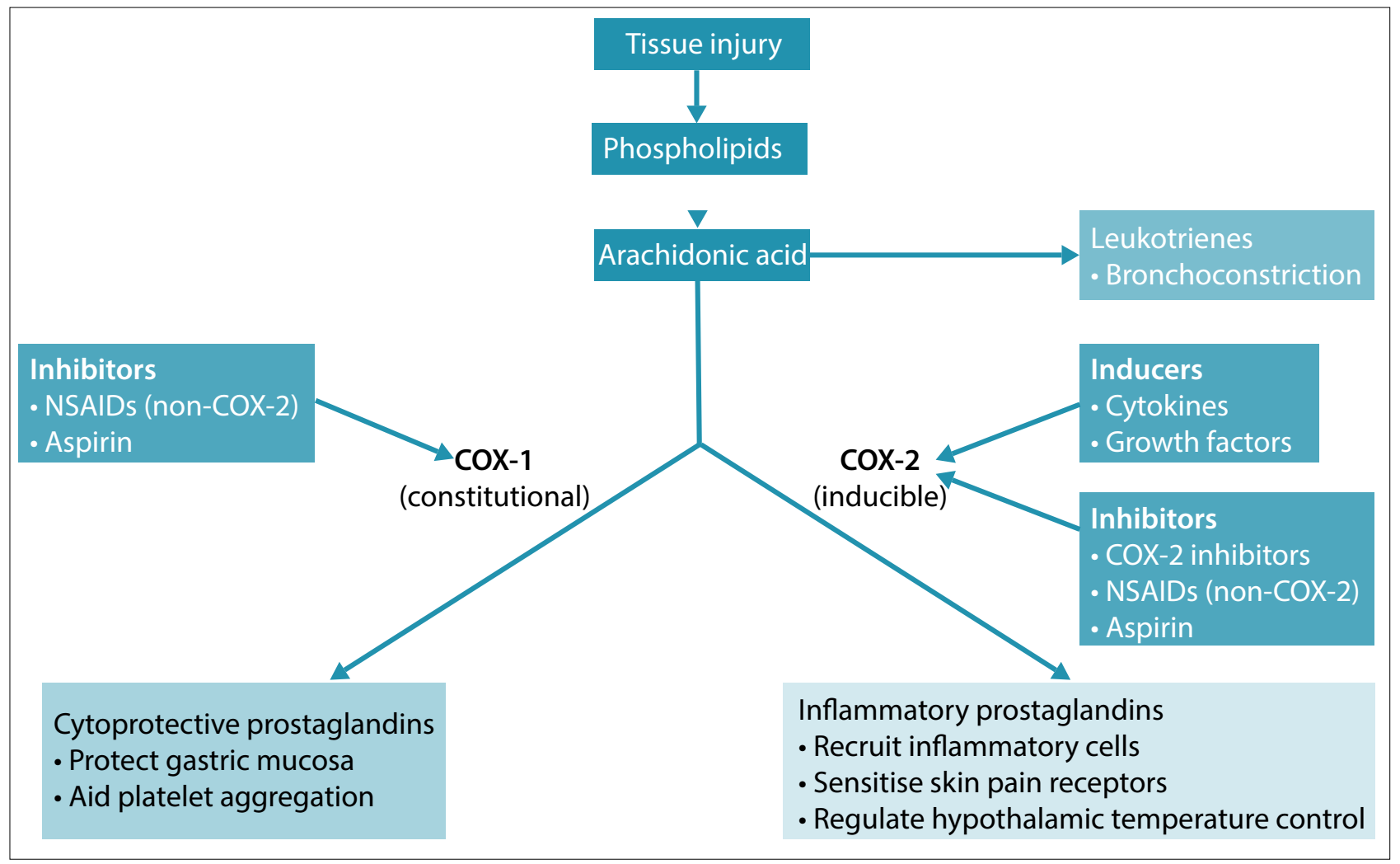

Fig. 2. The prostaglandin pathway. 
For risk factors for acute vasomotor renal failure induced by NSAIDs, see Table 9.

\section{COX-2: Renal}

In knock-out mouse models with renal disease the pathology shows fibrosis, inflammation and papillary changes. Clinical studies have shown oedema that resolves with drug withdrawal.

\section{Drug-induced acute interstitial nephritis}

The features are renal impairment with tubular function defect, such as acidosis, increased potassium level, and decreased urinary concentration ability. There may be fever, skin rash, eosinophilia or eosinophiluria (allergic reaction). The kidneys are of normal size (as the condition is acute, there is no time for the kidneys to shrink), with proteinuria of $<2$ g/day. The condition may occur within hours and is reversible in most cases. There is interstitial oedema with polymorph infiltration and eosinophils.

The drugs that induce acute interstitial nephritis are given in Table 10.

\section{Diagnosis}

- Reversal of renal failure after discontinuing the drug.

- Renal biopsy (if the cause of acute renal failure is uncertain, or known but a biopsy is taken to ascertain that there are no other causes).

\section{Treatment}

- Withdrawal of the drug.

- Corticosteroid (30 - 60 mg/day).

- Supportive dialysis if needed (temporarily in acute renal failure).

\section{Drug-induced chronic interstitial nephritis \\ Features There is a cumulative effect with repeated administration. The risk can be reduced by using acetylcysteine. ${ }^{[2]}$}

- Renal impairment that leads to end-stage renal disease (ESRD).

- Small-size kidneys, with proteinuria $<2$ g/day.

- Tubular function defect.

- Occurs within months or year.

- Not reversible, so if left untreated it will lead to ESRD.

- Pathology.

- Tubular atrophy and interstitial fibrosis (there is no eosinophilia).

Possible causes

Analgesics, NSAIDs, cisplatin, cyclosporine.

\section{Aminoglycosides}

The aminoglycosides are highly effective antimicrobials that are bactericidal, but nephrotoxic and ototoxic, with a narrow therapeutic range. When prescribing aminoglycosides, a once-daily regimen is recommended in patients with normal kidneys. There is a

Table 10. Drug-induced acute interstitial nephritis high peak concentration-enhancing efficacy with a long postdose effect. A single daily dose is less nephrotoxic. The dose depends on size and renal function. It is important to measure aminoglycoside levels.

\section{Intravenous contrast}

It is commonly used for computed tomography scanning, intravenous urography and angiography. It is unsafe in patients with preexisting renal impairment. The risk increases in diabetic nephropathy, heart failure and dehydration. Contrast can precipitate ESRF.

\section{Prescribing in kidney disease \\ Patients include those: \\ - with renal impairment \\ - on dialysis \\ - with renal transplants.}

\section{Principles}

It is important to establish the type of kidney disease. Most patients with kidney failure are taking a number of drugs. Therefore, interactions are common and care needs to be taken to avoid drug toxicity. Patients with renal impairment and renal failure are often also taking antihypertensive drugs and phosphate binders.

\section{Dosing in renal impairment}

The loading dose does not usually need to be changed. Maintenance doses or the dosing

Table 9. Risk factors for acute vasomotor renal failure induced by NSAIDs

\begin{tabular}{ll}
\hline Decreased EABV & Normal or increased EABV \\
\hline - Congestive heart failure & - Chronic kidney disease \\
- Cirrhosis & - Glomerulonephritis \\
- Nephrotic syndrome & - The elderly \\
- Sepsis & - Contrast-induced nephropathy \\
- Haemorrhage & - Obstructive uropathy \\
- Diuretic therapy & - Cyclosporine, tacrolimus use \\
- Postoperative patients (with third-space fluid loss) & \\
- Volume depletion/hypotension & \\
EABV = effective arterial blood volume. &
\end{tabular}

\begin{tabular}{lll}
\hline & Classes & \\
\hline Antibiotics & Diuretics & Others \\
\hline Penicillins & Furosemide & Captopril \\
Cephalosporins & Thiazides & Amphotericin B \\
Rifampicin & & NSAIDs \\
Sulfonamides & & \\
Ciprofloxacin & &
\end{tabular}

interval may have to be adjusted. The halflife is often prolonged. Therefore, reduce the dose or increase the dosing interval. Some drugs have active metabolites that are excreted renally, e.g. warfarin and diazepam.

\section{Amphotericin}

Amphotericin is an antifungal agent for topical and systemic use. It is a lipid-soluble drug that binds steroid alcohols (ergosterol) in the fungal cell membrane, causing leakage of cellular content and death. It is effective against Candida species and is both fungistatic and fungicidal, depending on the concentration. It has a broad spectrum of activity (Candida, Cryptosporidium).

It is administered intravenously for systemic invasive fungal infections and can be used orally for gastrointestinal mycosis.

Side-effects include local/systemic effects with infusion (fever). It can cause chronic kidney dysfunction, with a decline in GFR with prolonged use. Other effects include tubular dysfunction (membrane permeability), hypokalaemia, renal tubular acidosis (bicarbonate wasting type 1/distal), diabetes insipidus, and hypomagnesaemia.

Caution should be taken with prehydration/ saline loading to avoid problems. Toxicity can be further reduced substantially by liposomal packaging of amphotericin.

\section{Lithium}

Lithium carbonate is used for the treatment of bipolar mood disorder. Its toxicity is closely related to serum levels. Symptoms and signs include cardiovascular arrhythmias 
Table 11. Renal toxicity of antiviral therapy

\begin{tabular}{|c|c|c|c|}
\hline Antiretroviral class & Antiretroviral therapy & Renal effect & Clinical recommendations \\
\hline \multirow[t]{3}{*}{ Protease inhibitors } & Indinavir & $\begin{array}{l}\text { Nephrolithiasis, crystalluria, dysuria, } \\
\text { papillary necrosis, acute kidney injury, } \\
\text { interstitial nephritis } \\
\text { Ritonavir/lopinavir may increase toxicity of } \\
\text { indinavir }\end{array}$ & Daily fluid intake of $>2 \mathrm{~L} /$ day \\
\hline & Ritonavir & $\begin{array}{l}\text { Reversible acute renal failure (usually in } \\
\text { combination with nephrotoxic drugs) }\end{array}$ & \\
\hline & Saquinavir, nelfinavir & Renal calculi (rare) & Increased fluid intake \\
\hline \multirow[t]{2}{*}{$\begin{array}{l}\text { Reverse transcriptase } \\
\text { inhibitors }\end{array}$} & Tenofovir, abacavir & $\begin{array}{l}\text { Renal tubular damage: proximal tubular } \\
\text { dysfunction, Fanconi syndrome, } \\
\text { nephrogenic diabetes insipidus, acute } \\
\text { tubular necrosis, acute renal failure }\end{array}$ & $\begin{array}{l}\text { Patients on tenofovir should be monitored } \\
\text { for signs of tubular dysfunction (glycosuria, } \\
\text { acidosis, mild increase in plasma creatinine } \\
\text { level, and proteinuria) }\end{array}$ \\
\hline & $\begin{array}{l}\text { Didanosine, lamivudine, } \\
\text { stavudine }\end{array}$ & Isolated case reports of tubular dysfunction & \\
\hline Other & Cidofovir, adefovir & $\begin{array}{l}\text { Renal tubular damage, proximal tubular } \\
\text { dysfunction (cidofovir) }\end{array}$ & \\
\hline
\end{tabular}

(especially junctional dysarrhythmias) and central nervous system tremor, confusion, coma and neprhrogenic diabetes insipidus.

Treatment is supportive and includes haemodialysis and colonic irrigation for very high levels. There is inadvertent toxicity from interactions with ACE inhibitors, and loop and thiazide diuretics. Carbamazepine and other anti-epileptics increase neurotoxicity.

\section{Digoxin}

Digoxin toxicity (high levels) is demonstrated in $10 \%$ of patients and toxicity has been reported in $4 \%$ of a series of 4000 digoxin samples assayed.

The pharmacokinetics include a large volume of distribution (reservoir is skeletal muscle). About $30 \%$ of stores are excreted in urine per day.

Treatment of digoxin toxicity includes supportive correction of electrolyte imbalance. Atropine should be administered for bradycardia, and stimulants should be avoided because of arrhythmogenicity. Absorption can be limited with the use of charcoal (or cholestyramine) within 8 hours. Specific measures include the use of digoxin immune fab (Digibind and DigiFab) (digoxin-specific antibodies), which binds plasma digoxin, and the complex is eliminated by the kidney. These antibodies are used when serum drug values approach those of an overdose or are near arrest levels. Furthermore, digoxin elimination can be enhanced by using charcoal/cholestyramine to interrupt enterohepatic cycling. Dialysis is ineffective.

\section{Antituberculosis drugs}

Tuberculosis can be a difficult therapeutic problem in patients with renal failure. Rifampicin and isoniazid may be given in the normal dosage. Neither is cleared significantly by dialysis. Pyridoxine should be given with isoniazid to prevent peripheral neuropathy. The plasma half-life of ethambutol is prolonged in renal impairment. If the GFR is $<30 \mathrm{~mL} / \mathrm{min}$, the dose should be $10-15 \mathrm{mg} / \mathrm{kg} /$ day, with a further reduction to $4 \mathrm{mg} / \mathrm{kg} /$ day if the GFR is $<10 \mathrm{~mL} / \mathrm{min}$.
Although $10 \mathrm{mg} / \mathrm{kg} /$ day has been used at these levels of GFR, cases of optic atrophy have been reported. Ethambutol is not dialysed to any significant extent. Pyrazinamide should be given at a reduced dose $(10-15 \mathrm{mg} / \mathrm{kg})$. Capreomycin is a second-line drug, which can be used in isoniazid or streptomycin resistance. It is, however, nephrotoxic and ototoxic, but can be administered in a single dose of $500 \mathrm{mg}$. In patients receiving multiple transplants, and who are on cyclosporine, rifampicin cannot be used as it reduces the concentration of cyclosporine very substantially as a result of hepatic enzyme induction. The necessity to use more than three agents will be dictated by the nature and severity of the infection. Treatment may need to be prolonged ( 9 - 12 months) in uraemic or immunosuppressed patients, in contrast to the shorter courses that are preferred in patients with normal renal function.

\section{Antiretroviral therapy (ART)}

Renal toxicity of antiviral therapy is shown in Table 11.

Refer also to the Table on dose adjustments for ART in CKD and ESRD in the HIV and CKD section of the article 'Important causes of CKD in South Africa. ${ }^{\left[{ }^{[3]}\right.}$

\section{Other drugs}

Intravenous iodinated radiocontrast agents labelled with gadolinium are used as contrast media in patients undergoing MRI scans. Gadolinium is contraindicated in patients with stages 4 and 5 CKD, as it can result in a diffuse systemic fibrosis (sclerosis-like syndrome with quadriplegia and eventual death). It is perfectly acceptable to perform an MRI without contrast if indicated.

\section{References}

1. Pitt B, Zannad F, Remme W, et al. The effect of spironolactone on morbidity and mortality in patients with severe heart failure. New Engl J Med 1999;341(10):709-717.

2. Tepel M, van der Giet M, Schwarzfeld C, Laufer U, Liermann D, Zidek W. Prevention of radiographic-contrast-agent-induced reductions in renal function by acetylcysteine. $\mathrm{N}$ Engl $\mathrm{J}$ Med 2000;343(3):180-184

3. Moosa MR, Van der Walt I, Naicker S, Meyers AM. Important causes of chronic kidney disease in South Africa. S Afr Med J 2015;105(4):320. [http://dx.doi.org/10.7196/SAMJ.9535] 